\title{
Valve-sparing root replacement in type A dissection: Age and experience matter
}

\author{
Gal Levy, MD, and Abe DeAnda, Jr, MD
}

\author{
From the Division of Cardiovascular and Thoracic Surgery, UTMB-Galveston, Galveston, Tex. \\ Disclosures: Authors have nothing to disclose with regard to commercial support. \\ Received for publication Oct 10, 2018; accepted for publication Oct 11, 2018. \\ Address for reprints: Abe DeAnda, Jr, MD, Division of Cardiothoracic Surgery, UTMB-Galveston, 301 Univer- \\ sity Blvd, Galveston, TX 77551 (E-mail: abdeanda@utmb.edu). \\ J Thorac Cardiovasc Surg 2019;157:24-5 \\ $0022-5223 / \$ 36.00$ \\ Copyright (c) 2018 by The American Association for Thoracic Surgery \\ https://doi.org/10.1016/j.jtcvs.2018.10.043
}

Acute Stanford type A aortic dissection (TAAD) is a potentially lethal and relatively infrequent acute aortic syndrome, estimated to occur in the United States at a rate of 2 to 3.5 cases per 100,000 patient-years. ${ }^{1}$ Although this would translate into approximately 6000 patients a year, the number of patients presenting for therapy is between 2000 and 2500 , with the majority being treated surgically. Surgical mortality for TAAD has trended downward as experience and perioperative care have improved, with the International Registry of Acute Aortic Dissection showing a decrease in mortality during a 17 -year period from $25 \%$ to $18 \%,{ }^{2}$ although this most likely underestimates the "real-world" rate. ${ }^{3}$ The introduction of dedicated aortic specialists has led to further reductions in mortality to less than $10 \%{ }^{4}$

In this issue of the Journal, the Emory group of Rosenblum and colleagues ${ }^{5}$ present their single-institution experience with the subgroup of patients with TAAD who required root replacement. They further subdivided this cohort into those patients in whom the root was addressed with a composite valved conduit (conduit root group) and those who underwent a valve-sparing root replacement (VSRR group). ${ }^{5}$ The results demonstrated superior 30-day mortality in the VSRR group relative to the conduit root group $(3.4 \%$ vs $14.3 \%$, respectively; $P<.001)$. The important finding here may not be so much the superiority of the David procedure for addressing the root at the time of surgery for TAAD, but rather that in both groups the operative mortality was less than might be expected. Patient outcomes were therefore skewed in part by the obvious expertise of the surgeons involved.

This study was by no means clean of bias. The patients in the VSRR group were younger than those in the conduit root group and, by inclusion criteria, had valvular anatomy that was optimal for repair. In addition, 2 surgeons performed $82 \%$ of the VSRR procedures, whereas the conduit root replacement procedures were performed by a larger array of surgeons. Rosenblum and colleagues ${ }^{5}$ appropriately address these biases in their limitation section. At

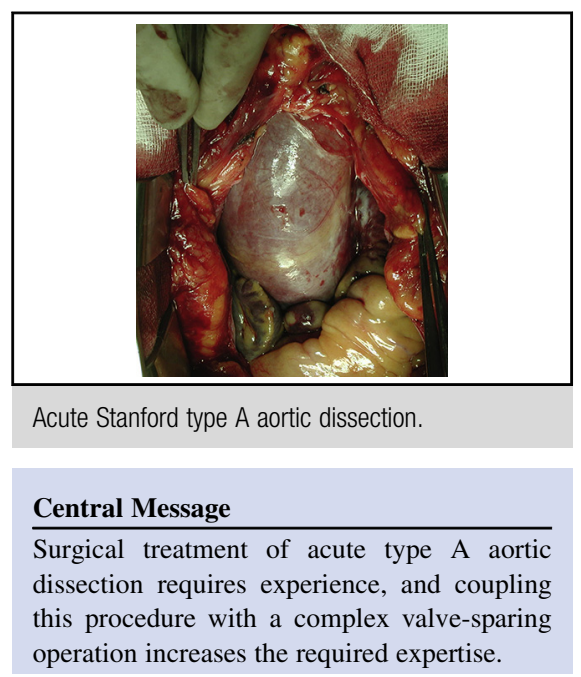

See Article page 14.

9 years, the differences in characteristics between the groups became amplified, with a significant difference in survival $(92 \%$ in the VSRR group vs $59 \%$ in the conduit root group; $P=.02$ ) providing a surrogate of sorts for predicting long-term survival.

The finding of a benefit of VSRR relative to conduit root replacement is not new. ${ }^{6,7}$ The information provided by this study, coupled with data from other studies looking at surgeon expertise ${ }^{4,8}$ and center volume ${ }^{9}$ could reasonably conclude that for patients with TAAD, VSRR is a preferable approach if the patient's preoperative characteristics are favorable, if the surgeon has the expertise, and if the institution has the volume experience. These caveats are not unreasonable, and as Rosenblum and colleagues ${ }^{5}$ at Emory have shown, optimal.

\section{References}

1. Hiratzka LF, Bakris GL, Beckman JA, Bersin RM, Carr VF, Casey DE Jr, et al; American College of Cardiology Foundation/American Heart Association Task Force on Practice Guidelines; American Association for Thoracic Surgery; American College of Radiology; American Stroke Association; Society of Cardiovascular Anesthesiologists; Society for Cardiovascular Angiography and Interventions; Society of Interventional Radiology; Society of Thoracic Surgeons; Society for Vascular Medicine. 2010 ACCF/AHA/AATS/ACR/ASA/SCA/SCAI/ SIR/STS/SVM guidelines for the diagnosis and management of patients with thoracic aortic disease. A Report of the American College of Cardiology Foundation/American Heart Association Task Force on Practice Guidelines, American Association for Thoracic Surgery, American College of Radiology, American Stroke Association, Society of Cardiovascular Anesthesiologists, Society for Cardiovascular Angiography and Interventions, Society of Interventional Radiology, Society of Thoracic Surgeons, and Society for Vascular Medicine. J Am Coll Cardiol. 2010;55:e27-129. Erratum in: J Am Coll Cardiol. 2013;62:1039-40. 
2. Pape LA, Awais M, Woznicki EM, Suzuki T, Trimarchi S, Evangelista A, et al. Presentation, diagnosis, and outcomes of acute aortic dissection: 17-year trends from the international registry of acute aortic dissection. J Am Coll Cardiol. 2015;66:350-8.

3. Evangelista A, Isselbacher EM, Bossone E, Gleason TG, Eusanio MD, Sechtem U, et al; IRAD Investigators. Insights from the international registry of acute aortic dissection: a 20-year experience of collaborative clinical research. Circulation. 2018;137:1846-60.

4. Beller JP, Scheinerman JA, Balsam LB, Ursomanno P, DeAnda A Jr. Operative strategies and outcomes in type A aortic dissection after the enactment of a multidisciplinary aortic surgery team. Innovations (Phila). 2015;10:410-5.

5. Rosenblum JM, Leshnower BG, Moon RC, Lasanajak Y, Binongo J, McPherson L, et al. Durability and safety of David V valve-sparing root replacement in acute type A aortic dissection. J Thorac Cardiovasc Surg. 2019;157:14-23.e1.
6. Subramanian S, Leontyev S, Borger MA, Trommer C, Misfeld M, Mohr FW Valve-sparing root reconstruction does not compromise survival in acute type A aortic dissection. Ann Thorac Surg. 2012;94:1230-4.

7. Waterford SD, Gardner RL, Moon MR. Extent of aortic replacement in type A dissection: current answers for an endless debate. Ann Thorac Surg. 2018;106: 1246-50.

8. Andersen ND, Ganapathi AM, Hanna JM, Williams JB, Gaca JG, Hughes GC. Outcomes of acute type A dissection repair before and after implementation of a multidisciplinary thoracic aortic surgery program. J Am Coll Cardiol. 2014; 63:1796-803.

9. Chikwe J, Cavallaro P, Itagaki S, Seigerman M, DiLuozzo G, Adams DH. National outcomes in aortic dissection: influence of surgeon and institutional volume on operative mortality. Ann Thorac Surg. 2013;95:1563-9. 